in vivo $35: 3475-3482(2021)$

doi:10.21873/invivo.12648

\title{
The Clinical Influence of the C-Reactive Protein-to-Albumin Ratio in Patients Who Received Curative Treatment for Gastric Cancer
}

\author{
TORU AOYAMA ${ }^{1,2^{*}}$, MASATO NAKAZONO $^{1,2^{*}}$, KENKI SEGAMI $^{1,2}$, SHINSUKE NAGASAWA $^{1,2}$, \\ KAZUKI KANO $^{1,2}$, TAKANOBU YAMADA ${ }^{1,2}$, YUKIO MAEZAWA ${ }^{1,2}$, KENTARO HARA $^{1,2}$, \\ ITARU HASHIMOTO $^{1,2}$, HIDEAKI SUEMATSU ${ }^{1,2}$, HAYATO WATANABE $^{1,2}$, KOSUKE TAKAHASHI $^{1}$, \\ MASAKATSU NUMATA ${ }^{1,2}$, HIROSHI TAMAGAWA ${ }^{1,2}$, NORIO YUKAWA $^{1,2}$, YASUSHI RINO $^{1,2}$, \\ TAKASHI OGATA ${ }^{2}$ and TAKASHI OSHIMA ${ }^{1,2}$ \\ ${ }^{1}$ Department of Surgery, Yokohama City University, Yokohama, Japan; \\ ${ }^{2}$ Department of Gastrointestinal Surgery, Kanagawa Cancer Center, Yokohama, Japan
}

\begin{abstract}
Background: We investigated the impact of the pre-surgical C-reactive protein-to-albumin ratio $(C A R)$ on survival and recurrence after curative treatment for gastric cancer. Patients and Methods: This study included 481 patients who underwent curative treatment for gastric cancer between 2013 and 2017. The risk factors for overall (OS) and recurrence-free (RFS) survival were identified. Results: A CAR of 0.05 was regarded as the optimal critical point of classification considering the 3-and 5-year survival rates and patients were divided according to their CAR. The OS rates at 3 and 5 years after surgery were significantly higher at $92.5 \%$ and $87.9 \%$, respectively, in the low-CAR group compared with $84.9 \%$ and $71.9 \%$, respectively, in the highCAR group. The corresponding RFS rates were $89.1 \%$ and $85.5 \%$, and $81.0 \%$ and $72.2 \%$, respectively, also a significant difference. A multivariate analysis demonstrated that the $C A R$ was a significant independent risk factor for the OS and marginally significant independent risk factor for the RFS. In addition, the incidences of pancreatic fistula and abdominal abscess were significantly higher and the rate of introduction of adjuvant chemotherapy significantly lower in
\end{abstract}

This article is freely accessible online.

*These Authors contributed equally to this article.

Correspondence to: Toru Aoyama, Department of Surgery, Yokohama City University, 3-9 Fukura, Kanazawa-ku, Yokohama 236-0004, Japan. Tel: +81 457872800, e-mail: t-aoyama@lilac.plala.or.jp and Takashi Oshima, Department of Gastrointestinal Surgery, Kanagawa Cancer Center, 2-3-2 Nakao, Asahi-ku, Yokohama, 241-8515, Japan. Tel: +81 455202222, e-mail: oshimat@kcch.jp

Key Words: Gastric cancer, C-reactive protein, albumin, survival. the high-CAR group. Conclusion: The CAR was a risk factor influencing survival in patients who underwent curative treatment for gastric cancer. An effective perioperative care plan and surgical strategy need to be developed according to the CAR.

Gastric cancer is the third-most common cancer and the second leading cause of cancer-related death worldwide (1, 2). Curative resection with lymphadenectomy and perioperative adjuvant treatment is the standard treatment for gastric cancer. However, almost $50 \%$ of patients develop recurrence, even after curative treatment $(3,4)$. To further improve the survival, new approaches as alternatives to conventional treatment need to be established.

In various malignancies, the preoperative host inflammatory status directly and indirectly affects tumor growth. Recent studies have also reported the preoperative inflammatory response to be related to tumor metastasis, tumor invasion, and chemotherapy resistance via damage to DNA, the promotion of angiogenesis, and the inhibition of apoptosis (5-8). In addition, some studies have shown that both short- and longterm oncological outcomes are affected by the inflammatory response during the perioperative period in gastrointestinal cancer $(9,10)$.

Several scoring systems for the preoperative inflammatory status, including the Glasgow Prognostic Score, platelet-tolymphocyte ratio, and neutrophil-to-lymphocyte ratio, have been developed, showing potential utility in predicting the survival of patients with gastric cancer (11-13). However, these scoring systems require complex calculations and use numerous perioperative elements, rendering them difficult to implement in daily clinical practice. Therefore, optimal tools for comprehensively evaluating the perioperative inflammatory status in gastric cancer treatment have not yet been established. 
Table I. Patient characteristics $(n=481)$.

\begin{tabular}{|c|c|c|c|c|}
\hline Characteristic & Whole cohort, n (\%) & CAR<0.05, n $(\%)(\mathrm{n}=381)$ & $\mathrm{CAR} \geq 0.05, \mathrm{n}(\%)(\mathrm{n}=100)$ & $p$-Value \\
\hline Age & & & & 0.132 \\
\hline$<65$ Years & $145(30.1 \%)$ & $121(31.8 \%)$ & $24(24.0 \%)$ & \\
\hline$\geq 65$ Years & $336(69.9 \%)$ & $260(68.2 \%)$ & $76(76.0 \%)$ & \\
\hline Gender & & & & 0.177 \\
\hline Male & $319(66.3 \%)$ & $247(64.8 \%)$ & $72(72.0 \%)$ & \\
\hline Female & $162(33.7 \%)$ & $134(35.2 \%)$ & $28(28.0 \%)$ & \\
\hline Pathological type & & & & 0.057 \\
\hline Intestinal & $243(50.5 \%)$ & $184(48.3 \%)$ & $59(59.0 \%)$ & \\
\hline Diffuse & $238(49.5 \%)$ & $197(51.7 \%)$ & $41(41.0 \%)$ & \\
\hline UICC T status & & & & 0.003 \\
\hline $\mathrm{T} 1$ & $301(62.6 \%)$ & $251(65.9 \%)$ & $50(50.0 \%)$ & \\
\hline $\mathrm{T} 2$ to $\mathrm{T} 3$ & $180(37.4 \%)$ & $130(34.1 \%)$ & $50(50.0 \%)$ & \\
\hline Lymph node metastasis & & & & 0.011 \\
\hline Negative & $347(72.1 \%)$ & $285(74.8 \%)$ & $62(62.0 \%)$ & \\
\hline Positive & $134(27.9 \%)$ & $96(35.2 \%)$ & $38(38.0 \%)$ & \\
\hline Lymphatic invasion & & & & 0.040 \\
\hline Negative & $334(69.4 \%)$ & $273(71.7 \%)$ & $61(61.0 \%)$ & \\
\hline Positive & $147(30.6 \%)$ & $108(38.3 \%)$ & $39(39.0 \%)$ & \\
\hline Vascular invasion & & & & 0.018 \\
\hline Negative & $276(57.4 \%)$ & $229(60.1 \%)$ & $47(47.0 \%)$ & \\
\hline Positive & $205(42.6 \%)$ & $152(39.9 \%)$ & $53(53.0 \%)$ & \\
\hline Postoperative complications & & & & 0.213 \\
\hline Yes & $68(14.1 \%)$ & $50(13.1 \%)$ & $18(18.0 \%)$ & \\
\hline No & $413(85.9 \%)$ & $331(86.9 \%)$ & $82(82.0 \%)$ & \\
\hline
\end{tabular}

CAR: C-Reactive protein-to-albumin ratio; UICC: Union for International Cancer Control.

Recently, the C-reactive protein-to-albumin ratio (CAR) was identified as a non-specific marker of systemic inflammation (14-16). CAR has been shown to have some clinical impact on both the short- and long-term oncological outcomes of patients with gastrointestinal cancer, including hepatocellular, esophageal, colorectal, and pancreatic, and some studies have shown similar tendencies for gastric cancer. However, few reports have described the prognostic value of the CAR in patients who undergo curative treatment for gastric cancer $(17,18)$. In addition, the mechanism underlying the relationship between the CAR and oncological outcomes in gastric cancer is unclear.

Given the above, we investigated whether or not overall (OS) and recurrence-free (RFS) survival were affected by the $\mathrm{CAR}$ and clarified the clinical course according to the CAR in patients who underwent curative treatment for gastric cancer.

\section{Patients and Methods}

Patients. Patients were selected based on the medical records of consecutive patients who underwent curative resection for gastric cancer at Kanagawa Cancer Center from 2013 to 2017. The inclusion criteria were as follows: (i) Histologically proven adenocarcinoma, (ii) clinical stage I to III disease as evaluated using according to the 15th edition of the general rules for gastric cancer published by the Japanese Gastric Cancer Association (19), (iii) curative gastrectomy for gastric cancer as a primary treatment, (iv) complete (R0) resection of gastric cancer with radical lymph node dissection, and (v) $\geq 16$ harvested lymph nodes.

Surgical procedure and adjuvant treatment. All patients underwent total or distal gastrectomy with nodal dissection. D1+ nodal dissection was performed for those with clinical stage IA disease, and D2 dissection was performed for those with clinical stage IB or higher disease. Patients diagnosed with pathological II and III disease received S-1-based adjuvant chemotherapy within 6 weeks after surgery.

Measurement of the CAR. The CAR was calculated as the serum CRP level $(\mathrm{mg} / \mathrm{dl})$ divided by the serum albumin level $(\mathrm{g} / \mathrm{dl})$ measured 1 week before surgery.

Follow up. Patients were followed-up at outpatient clinics. Hematological tests and physical examinations were performed at least every 3 months for 5 years. The levels of carcinoembryonic antigen and CA19 9 tumor marker were also checked at least every 3 months for 5 years. Patients underwent a computed tomography examination every 6 to 12 months until 5 years after surgery

Evaluations and statistical analyses. The significance of differences between the CAR and clinicopathological parameters was determined using the chi-squared test. The Kaplan-Meier method 
Table II. Univariate and multivariate Cox proportional hazards analysis of clinicopathological factors for overall survival.

\begin{tabular}{|c|c|c|c|c|c|c|c|}
\hline \multirow[t]{2}{*}{ Factor } & \multirow[t]{2}{*}{ No } & \multicolumn{3}{|c|}{ Univariate analysis } & \multicolumn{3}{|c|}{ Multivariate analysis } \\
\hline & & OR & $95 \% \mathrm{CI}$ & $p$-Value & OR & $95 \% \mathrm{CI}$ & $p$-Value \\
\hline Age & & & & 0.125 & & & \\
\hline$<65$ Years & 145 & 1.000 & & & & & \\
\hline$\geq 65$ Years & 336 & 1.568 & $0.883-2.786$ & & & & \\
\hline Gender & & & & 0.219 & & & \\
\hline Male & 162 & 1.000 & & & & & \\
\hline Female & 319 & 1.403 & $0.818-2.409$ & & & & \\
\hline Pathological type & & & & 0.049 & & & \\
\hline Intestinal & 243 & 1.000 & & & & & \\
\hline Diffuse & 238 & 1.634 & $1.003-2.664$ & & & & \\
\hline UICC T status & & & & $<0.001$ & & & 0.049 \\
\hline $\mathrm{T} 1$ & & 1.000 & & & 1.000 & & \\
\hline $\mathrm{T} 2$ to $\mathrm{T} 3$ & & 4.553 & $2.695-7.691$ & & 1.871 & $1.002-3.494$ & \\
\hline Lymph node metastasis & & & & $<0.001$ & & & $<0.001$ \\
\hline Negative & 347 & 1.000 & & & 1.000 & & \\
\hline Positive & 134 & 5.166 & $3.144-8.489$ & & 2.860 & $1.635-5.004$ & \\
\hline CAR & & & & $<0.001$ & & & 0.027 \\
\hline$<0.05$ & 381 & 1.000 & & & 1.000 & & \\
\hline$\geq 0.05$ & 100 & 2.397 & $1.461-3.934$ & & 1.762 & $1.067-2.909$ & \\
\hline Lymphatic invasion & & & & $<0.001$ & & & \\
\hline Negative & 334 & 1.000 & & & & & \\
\hline Positive & 147 & 3.056 & $1.886-4.951$ & & & & \\
\hline Vascular invasion & & & & $<0.001$ & & & 0.015 \\
\hline Negative & 276 & 1.000 & & & 1.000 & & \\
\hline Positive & 205 & 4.232 & $2.463-7.270$ & & 2.120 & $1.155-3.890$ & \\
\hline Postoperative complications & & & & 0.811 & & & \\
\hline Yes & 68 & 1.000 & & & & & \\
\hline No & 413 & 1.089 & $0.540-2.199$ & & & & \\
\hline
\end{tabular}

CAR: C-Reactive protein-to-albumin ratio; CI: confidence intervaI; OR: odds ratio; UICC: Union for International Cancer Control.

was used to calculate the OS and RFS curves. Univariate and multivariate survival analyses were performed using a Cox proportional hazards model. $p$-Values of less than 0.05 were considered to indicate statistical significance. The SPSS software program (v27.0 J Win; IBM, Armonk, NY, USA) was used for all statistical analyses. This study was approved by the IRB of Kanagawa Cancer Center (2019-eki-176).

\section{Results}

Patients. We evaluated 481 patients in the present study. The median age was 68 (range $=32-90$ ) years, and 319 patients were male. The median follow-up period was 62.7 months. The median length of surgery was 267 minutes. The median blood loss was $90 \mathrm{ml}$. The median number of harvested lymph nodes was 44 .

Survival analyses and recurrence patterns. The OS stratified by each clinical factor was compared using the log-rank test, and a significant difference was observed using a CAR of 0.05 . On comparing the patient backgrounds between the high-CAR $(\mathrm{CAR} \geq 0.05)$ and low-CAR $(\mathrm{CAR}<0.05)$ groups, significant differences were noted in the pathological T status, $\mathrm{N}$ status, and lymphovascular invasion in the high-CAR group (Table I).

Each clinicopathological factor was categorized as shown in Table II and analyzed for its prognostic significance. The univariate analyses for the OS showed that pathological $\mathrm{T}$ factor, pathological $\mathrm{N}$ factor, histological type, lymphovascular invasion, and CAR were significant prognostic factors. The CAR was therefore selected for the final multivariate analysis model. The OS rates at 3 and 5 years after surgery were significantly higher at $92.5 \%$ and $87.9 \%$, respectively, for the low-CAR group, than those of $84.9 \%$ and $71.9 \%$, respectively, for the high-CAR group. The OS curves are shown in Figure 1.

The univariate analyses for RFS showed that the CAR was a significant prognostic factor. The CAR was selected as a marginally significant prognostic factor for the final multivariate analysis model (Table III). The RFS rates at 3 and 5 years after surgery were higher at $89.1 \%$ and $85.5 \%$ respectively, for the low-CAR group, compared with $81.0 \%$ and $72.2 \%$, respectively, for the high-CAR group, a marginally significant difference $(p=0.065)$. The RFS curves are shown in Figure 2. 


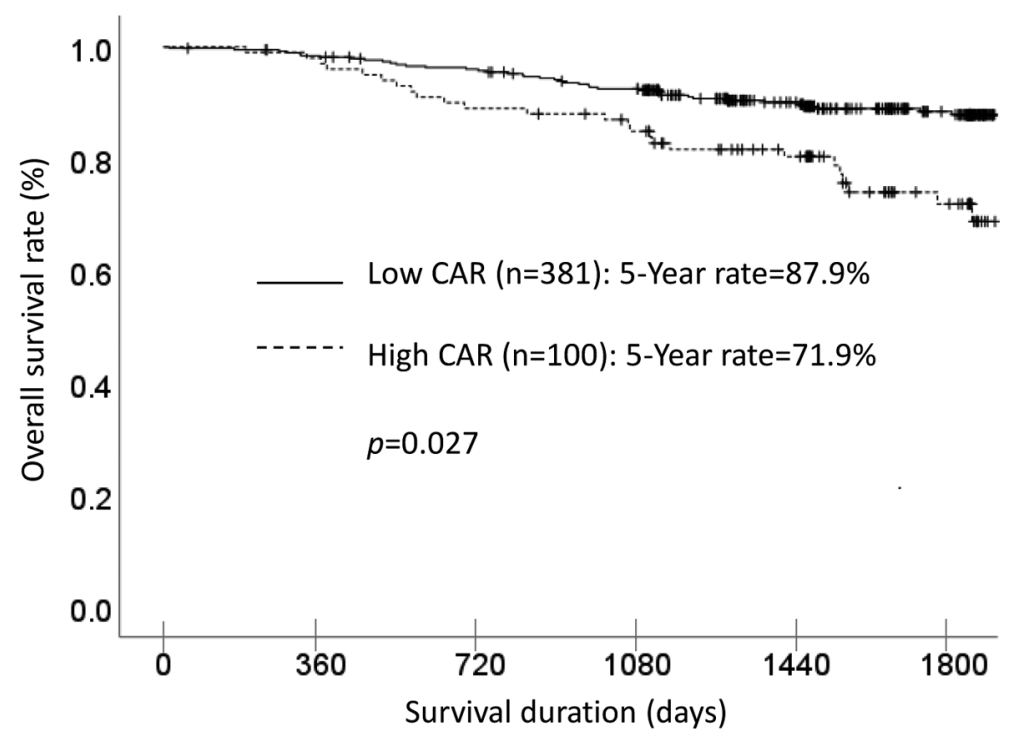

Figure 1. A comparison of overall survival in patients with a high C-reactive protein-to-albumin ratio $(C A R(\geq 0.05)$ vs. those with a low CAR $(<0.05)$.

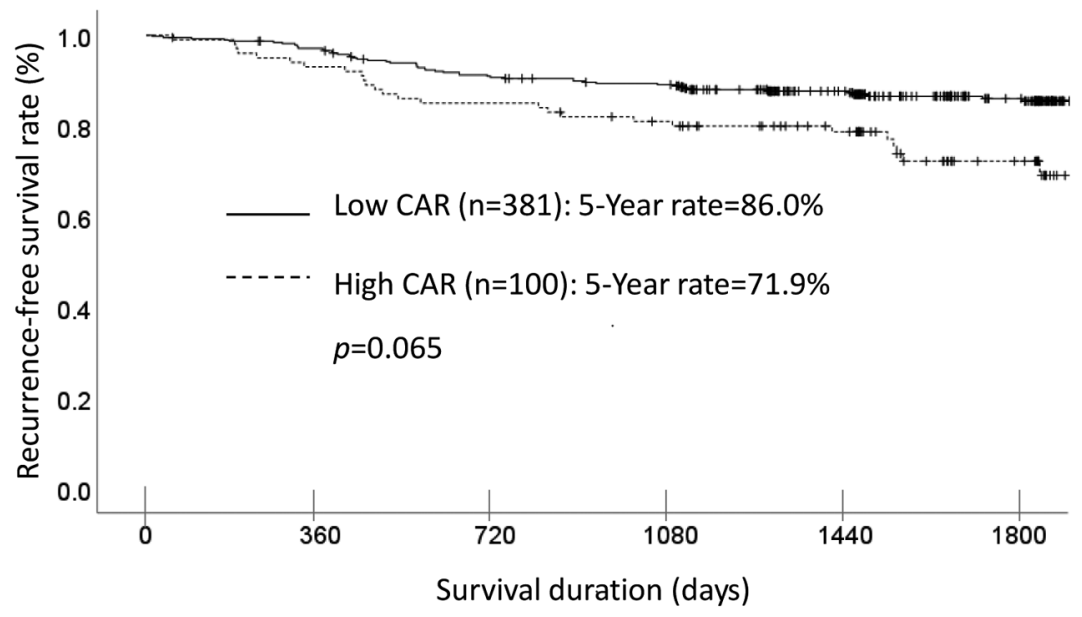

Figure 2. A comparison of recurrence-free survival in patients with a high C-reactive protein-to-albumin ratio (CAR $(\geq 0.05) v s$. those with a low $C A R(<0.05)$.

Postoperative course of the low- and high-CAR groups. When comparing the postoperative course between the two groups, there were some differences in the incidence of postoperative surgical complications and details of adjuvant chemotherapy. The incidences of pancreatic fistula and abdominal abscess were $8 \%(8 / 100)$ and $4 \%$ (4/100), respectively, in the high-CAR group but $3.2 \%(12 / 381)$ and $1.0 \%$ (4/381), respectively, in the low-CAR group. The incidences of these surgical complications were significantly higher in the high-CAR group than in the low-CAR group $(p=0.031$ and $p=0.040$, respectively).

Furthermore, in the present study, there were 126 patients who were eligible for postoperative adjuvant treatment. Among those 126 patients (37 in the high-CAR group and 89 in the low-CAR group), 24 refused adjuvant treatment. The incidence of refusal of adjuvant treatment was significantly ( $p=0.049)$ higher at $29.7 \%(11 / 37)$ in the highCAR group compared with $14.6 \%(13 / 89)$ in the low-CAR 
Table III. Univariate and multivariate Cox proportional hazards analysis of clinicopathological factors for recurrence free survival.

\begin{tabular}{|c|c|c|c|c|c|c|c|}
\hline \multirow[t]{2}{*}{ Factor } & \multirow[t]{2}{*}{ No } & \multicolumn{3}{|c|}{ Univariate analysis } & \multicolumn{3}{|c|}{ Multivariate analysis } \\
\hline & & OR & $95 \% \mathrm{CI}$ & $p$-Value & OR & $95 \% \mathrm{CI}$ & $p$-Value \\
\hline Age & & & & 0.136 & & & \\
\hline$<65$ Years & 145 & 1.000 & & & & & \\
\hline$\geq 65$ Years & 336 & 1.493 & $0.882-2.529$ & & & & \\
\hline Gender & & & & 0.382 & & & \\
\hline Male & 162 & 1.000 & & & & & \\
\hline Female & 319 & 1.242 & $0.764-2.021$ & & & & \\
\hline Pathological type & & & & 0.078 & & & \\
\hline Intestinal & 243 & 1.000 & & & & & \\
\hline Diffuse & 238 & 1.499 & $0.956-2.350$ & & & & \\
\hline UICC T status & & & & $<0.001$ & & & 0.003 \\
\hline $\mathrm{T} 1$ & & 1.000 & & & 1.000 & & \\
\hline $\mathrm{T} 2$ to $\mathrm{T} 3$ & & 3.961 & $2.471-6.349$ & & 2.292 & $1.336-3.932$ & \\
\hline Lymph node metastasis & & & & $<0.001$ & & & $<0.001$ \\
\hline Negative & 347 & 1.000 & & & 1.000 & & \\
\hline Positive & 134 & 4.579 & $2.912-7.199$ & & 2.924 & $1.744-4.901$ & \\
\hline CAR & & & & 0.003 & & & 0.065 \\
\hline$<0.05$ & 381 & 1.000 & & & 1.000 & & \\
\hline$\geq 0.05$ & 100 & 2.022 & $1.236-3.239$ & & 1.566 & $0.972-2.522$ & \\
\hline Lymphatic invasion & & & & $<0.001$ & & & \\
\hline Negative & 334 & 1.000 & & & & & \\
\hline Positive & 147 & 2.991 & $1.915-4.671$ & & & & \\
\hline Vascular invasion & & & & $<0.001$ & & & \\
\hline Negative & 276 & 1.000 & & & & & \\
\hline Positive & 205 & 3.498 & $2.161-5.662$ & & & & \\
\hline Postoperative complications & & & & 0.956 & & & \\
\hline Yes & 68 & 1.000 & & & & & \\
\hline No & 413 & 1.018 & $0.538-1.925$ & & & & \\
\hline
\end{tabular}

CAR: C-Reactive protein-to-albumin ratio; CI: confidence intervaI; OR: odds ratio; UICC: Union for International Cancer Control.

Table IV. Patterns of recurrence between the patients with low <0.05) and high ( $\geq 0.05)$ C-reactive protein-to-albumin ratio $(C A R)$.

\begin{tabular}{|c|c|c|c|c|}
\hline \multirow[b]{2}{*}{ Recurrence site } & \multirow[b]{2}{*}{ All cases $(n=481), n(\%)$} & \multicolumn{2}{|c|}{ CAR, n (\%) } & \multirow[b]{2}{*}{$p$-Value } \\
\hline & & $<0.05(\mathrm{n}=381)$ & $\geq 0.05(\mathrm{n}=100)$ & \\
\hline Peritoneal & $22(4.6 \%)$ & $15(3.9 \%)$ & $7.0 \%$ & 0.192 \\
\hline Hematological & $15(3.1 \%)$ & $10(2.6 \%)$ & $5.0 \%$ & 0.950 \\
\hline Lymph node & $10(2.1 \%)$ & $8(2.1 \%)$ & $2.0 \%$ & 0.224 \\
\hline Local site & $9(1.9 \%)$ & $7(1.8 \%)$ & $2.0 \%$ & 0.915 \\
\hline Total & 56 & 40 & & \\
\hline
\end{tabular}

group. However, there was no significant difference in the site of first relapse between the two groups (Table IV).

\section{Discussion}

The present study explored whether or not the CAR clinically influences OS or RFS in patients who received curative treatment for gastric cancer. The major finding was that the CAR was an independent risk factor for OS and marginally significant independent risk factor for RFS. In addition, the incidences of pancreatic fistula and abdominal abscess were significantly higher and the introductions of adjuvant chemotherapy significantly lower for the high-CAR group than in the low-CAR group. Therefore, the CAR appears to be 
a promising clinical prognostic marker for patients who received curative treatment for gastric cancer, and patients with a high CAR seem to require much more attention in the postoperative clinical course than those with low CAR.

In the present study, the hazard ratio (HR) for a high CAR in OS was 1.762 [95\% confidence interval $(\mathrm{CI})=1.067$ 2.909], and that for the RFS was 1.566 (95\% CI=0.9722.522). Similar HRs for the CAR in gastric cancer were previously reported, ranging from 1.33 to $2.21(20,21)$. In resectable gastric cancer, Toiyama et al. evaluated the clinical impact of the CAR in 384 patients with stage I to III gastric cancer (22). They reported that a high CAR was a risk factor for poorer $\mathrm{OS}(\mathrm{HR}=2.21,95 \% \mathrm{CI}=1.19-4.11$; $p=0.011)$ and $\mathrm{RFS}(\mathrm{HR}=1.82,95 \% \mathrm{CI}=1.03-3.23 ; p=0.038)$. In metastatic gastric cancer, Baba et al. clarified the prognostic impact of the CAR in 123 patients with unresectable stage IV gastric cancer (23), demonstrating a high CAR to be an independent risk factor for poorer OS ( $\mathrm{HR}=1.11$, 95\% CI=1.03-1.18). Given these previous findings, the CAR appears to influence clinically the survival of patients with gastric cancer in both resectable and metastatic settings.

Regarding why the CAR affects the survival of patients with gastric cancer, our study results suggest several possible explanations. Firstly, the CAR status may have been correlated with postoperative infectious complications. In the present study, a high CAR was associated with the occurrence of pancreatic fistula and abdominal abscess. A similar result was observed in a previous study, where Toiyama et al. found that a high CAR influenced the occurrence of postoperative surgical site infection in gastric cancer. Furthermore, those authors reported that a high CAR was an independent risk factor for surgical site infection (22). In addition, Lee et al. evaluated the relationship between the CAR and perioperative surgical complications in 128 patients with gastric cancer (24). They demonstrated that the CAR was an independent prognostic factor of perioperative surgical complications ( $\mathrm{HR}=2.832, p=0.045)$. Recently, other studies have reported that the occurrence of postoperative surgical complications influences the recurrence pattern and patient survival in various malignancies $(25,26)$. Therefore, patients with a high CAR tend to more frequently develop postoperative surgical complications compared to those with a low CAR, and the occurrence of surgical complications might then lead to a poor prognosis. A second possible reason was that the CAR was correlated with the introduction of postoperative adjuvant chemotherapy. Pivotal studies have demonstrated the effectiveness of adjuvant chemotherapy for patients with locally advanced gastric cancer $(27,28)$, with the introduction of postoperative chemotherapy proving to be a key treatment in these patients. In the present study, the frequency of patients in whom adjuvant treatment could not be introduced was significantly higher for the high-CAR group than the low-CAR group (29.7\% vs. $14.6 \%, p=0.049)$. Therefore, the patients in the High-CAR group tended not to receive the clinical benefit of adjuvant chemotherapy. The preoperative CAR has been shown to influence the introduction of adjuvant chemotherapy. For example, Tominaga et al. found that the CAR influenced the occurrence of side-effects of adjuvant treatment in 136 patients with stage III colorectal cancer (29); the incidence of side-effects of grade $\geq$ III was $51.7 \%(15 / 29)$ in the highCAR group and $18.7 \%(20 / 107)$ in the low-CAR group. Given these findings, the CAR status might influence the decision to administer adjuvant chemotherapy. However, whether or not the CAR affected the continuation of adjuvant chemotherapy or the toxicity of adjuvant chemotherapy in the present study is unclear. Further studies focusing on this issue will therefore be needed.

The cut-off value of CAR was 0.05 in the present study; in previous studies, the cut-off value ranged from 0.02 to 0.58. For example, Saito et al. evaluated the CAR as a prognostic factor in 453 patients with stage I-IV gastric cancer, setting the cut-off value at 0.0232 according to a receiver operating characteristic analysis (30). Toiyama et al. evaluated the CAR as a prognostic factor in 384 patients with stage I-III gastric cancer (24), setting the cut-off value at 0.051 according to their own receiver operating characteristics analysis. In addition, Li et al. evaluated the CAR as a prognostic factor in 258 patients with stage IV gastric cancer (26), setting the cut-off value at 0.5897 . The difference in the cut-off value of CAR might be affected by several factors. Firstly, differences in patient background characteristics might be responsible. For example, Saito et al.'s study included patients with stage I-IV gastric cancer, while Toiyama et al.'s study and the present study only included those with stage I-III gastric cancer. Secondly, the treatment methods differed among studies. Patients only received chemotherapy in Li et al.'s study, while they underwent surgery and received adjuvant chemotherapy in the present study. Thirdly, the number of patients also differed among studies. To utilize the CAR to determine the optimum gastric cancer treatment strategy, it is essential to set and establish an ideal cut-off value. Thus, further studies will be needed in order to establish optimal evaluation methods and optimal cut-off values of the CAR in gastric cancer.

Several limitations associated with the present study warrant mention. Firstly, the present study was a retrospective analysis at a single institution. Thus, there might have been some selection bias among the patients in this series. Secondly, the timing of the evaluation of the CAR was not standardized, with measurements made from preoperative days 1 to 7 . This timing bias might have influenced the present study results. Given these limitations, the present results must be confirmed in another cohort. 
In conclusion, the preoperative CAR was shown to be a significant prognostic factor for patients who received curative treatment for gastric cancer. The preoperative CAR is a promising and useful tool for developing treatment strategies to optimize the management of patients with gastric cancer.

\section{Conflicts of Interest}

The Authors declare no conflicts of interest exist in association with the present study.

\section{Authors' Contributions}

TA and MN made substantial contributions to conception and design. TA, MN, KS, SN, HS, KK, TY, IH, HW, MN, HT, TO, KT, NY, TO and YR made substantial contributions to acquisition of data, or analysis and interpretation of data. TA, HW, MN, HT, TO, $\mathrm{NY}$ and YR were involved in drafting the article or revising it critically for important intellectual content. TA, NM, KK and TO gave final approval of the version to be published.

\section{Acknowledgements}

This work was supported by JSPS KAKENHI Grant Number $21 \mathrm{~K} 08688$.

\section{References}

1 Wong MCS, Huang J, Chan PSF, Choi P, Lao XQ, Chan SM, Teoh A and Liang P: Global incidence and mortality of gastric cancer, 1980-2018. JAMA Netw Open 4(7): e2118457, 2021. PMID: 34309666. DOI: 10.1001/jamanetworkopen.2021.18457

2 Bray F, Ferlay J, Soerjomataram I, Siegel RL, Torre LA and Jemal A: Global cancer statistics 2018: GLOBOCAN estimates of incidence and mortality worldwide for 36 cancers in 185 countries. CA Cancer J Clin 68(6): 394-424, 2018. PMID: 30207593. DOI: $10.3322 /$ caac. 21492

3 Pentheroudakis G and ESMO Guidelines Committee: Recent eUpdates to the ESMO Clinical Practice Guidelines on hepatocellular carcinoma, cancer of the pancreas, soft tissue and visceral sarcomas, cancer of the prostate and gastric cancer. Ann Oncol 30(8): 1395-1397, 2019. PMID: 31168599. DOI: 10.1093/annonc/mdz180

4 Muro K, Van Cutsem E, Narita Y, Pentheroudakis G, Baba E, Li J, Ryu MH, Zamaniah WIW, Yong WP, Yeh KH, Kato K, Lu Z, Cho BC, Nor IM, Ng M, Chen LT, Nakajima TE, Shitara K, Kawakami H, Tsushima T, Yoshino T, Lordick F, Martinelli E, Smyth EC, Arnold D, Minami H, Tabernero J and Douillard JY: Pan-Asian adapted ESMO Clinical Practice Guidelines for the management of patients with metastatic gastric cancer: a JSMOESMO initiative endorsed by CSCO, KSMO, MOS, SSO and TOS. Ann Oncol 30(1): 19-33, 2019. PMID: 30475956. DOI: 10.1093/annonc/mdy502

5 Grivennikov SI, Greten FR and Karin M: Immunity, inflammation, and cancer. Cell 140(6): 883-899, 2010. PMID: 20303878. DOI: 10.1016/j.cell.2010.01.025

6 Liu L, Yang L, Yan W, Zhai J, Pizzo DP, Chu P, Chin AR, Shen M, Dong C, Ruan X, Ren X, Somlo $G$ and Wang SE:
Chemotherapy induces breast cancer stemness in association with dysregulated monocytosis. Clin Cancer Res 24(10): 23702382, 2018. PMID: 29500278. DOI: 10.1158/1078-0432.CCR17-2545

7 Roxburgh CS and McMillan DC: Role of systemic inflammatory response in predicting survival in patients with primary operable cancer. Future Oncol 6(1): 149-163, 2010. PMID: 20021215. DOI: $10.2217 /$ fon.09.136

8 Chen W, Zhong S, Shan B, Zhou S, Wu X, Yang H and Ye S: Serum D-dimer, albumin and systemic inflammatory response markers in ovarian clear cell carcinoma and their prognostic implications. J Ovarian Res 13(1): 89, 2020. PMID: 32771026. DOI: $10.1186 / \mathrm{s} 13048-020-00693-\mathrm{w}$

9 Kano K, Aoyama T, Maezawa Y, Hayashi T, Yamada T, Tamagawa H, Sato T, Cho H, Yoshikawa T, Rino Y, Masuda M, Oshima T and Ogata T: Postoperative level of C-reactive protein is a prognosticator after esophageal cancer surgery with perioperative steroid therapy and enhanced recovery after surgery care. In Vivo 33(2): 587-594, 2019. PMID: 30804146. DOI: 10.21873/invivo.11515

10 Hara K, Aoyama T, Yamada T, Nakazono M, Nagasawa S, Shimoda Y, Kumazu Y, Numata M, Hayashi T, Tamagawa H, Shiozawa M, Morinaga S, Yukawa N, Rino Y, Masuda M, Ogata $\mathrm{T}$ and Oshima $\mathrm{T}$ : The prognostic value of the perioperative systemic inflammation score for patients with advanced gastric cancer. Anticancer Res 40(3): 1503-1512, 2020. PMID: 32132050. DOI: 10.21873/anticanres.14095

11 Shimoda Y, Fujikawa H, Komori K, Watanabe H, Kano K, Yamada T, Shiozawa M, Morinaga S, Katsumata K, Tsuchida A, Ogata T and Oshima T: Preoperative utility of the Glasgow Prognostic Score on outcomes of patients with locally advanced gastric cancer. J Gastrointest Cancer, 2021. PMID: 33460001. DOI: $10.1007 / \mathrm{s} 12029-021-00584-3$

12 Wang N, Xi W, Lu S, Jiang J, Wang C, Zhu Z, Yan C, Liu J and Zhang J: A novel inflammatory-nutritional prognostic scoring system for stage III gastric cancer patients with radical gastrectomy followed by adjuvant chemotherapy. Front Oncol 11: 650562, 2021. PMID: 34195071. DOI: 10.3389/fonc. 2021.650562

13 Inoue H, Kosuga T, Kubota T, Konishi H, Shiozaki A, Okamoto K, Fujiwara H and Otsuji E: Significance of a preoperative systemic immune-inflammation index as a predictor of postoperative survival outcomes in gastric cancer. World J Surg Oncol 19(1): 173, 2021. PMID: 34118953. DOI: 10.1186/s12957-021-02286-3

14 Tamai K, Okamura S, Makino S, Yamamura N, Fukuchi N, Ebisui C, Inoue A and Yano M: C-reactive protein/albumin ratio predicts survival after curative surgery in elderly patients with colorectal cancer. Updates Surg, 2021. PMID: 33677820. DOI: 10.1007/s13304-021-01011-9

15 Serafini S, Friziero A, Sperti C, Vallese L, Grego A, Piangerelli A, Belluzzi A and Moletta L: The ratio of C-reactive protein to albumin is an independent predictor of malignant intraductal papillary mucinous neoplasms of the pancreas. J Clin Med 10(10): 2058, 2021. PMID: 34064877. DOI: 10.3390/jcm10102058

16 Yasukawa K, Shimizu A, Motoyama H, Kubota K, Notake T, Fukushima K, Ikehara T, Hayashi H, Kobayashi A and Soejima Y: Preoperative C-reactive protein-to-albumin ratio predicts long-term outcomes in extrahepatic cholangiocarcinoma patients. J Surg Oncol 122(7): 1516-1517, 2020. PMID: 32960983. DOI: $10.1002 /$ jso. 26175 
17 Yu Q, Li KZ, Fu YJ, Tang Y, Liang XQ, Liang ZQ and Bai JH: Clinical significance and prognostic value of C-reactive protein/albumin ratio in gastric cancer. Ann Surg Treat Res 100(6): 338-346, 2021. PMID: 34136430. DOI: 10.4174/astr.2021.100.6.338

18 Liu X, Sun X, Liu J, Kong P, Chen S, Zhan Y and Xu D: Preoperative C-reactive protein/albumin ratio predicts prognosis of patients after curative resection for gastric cancer. Transl Oncol 8(4): 339-345, 2015. PMID: 26310380. DOI: 10.1016/j.tranon.2015. 06.006

19 Japanese Gastric Cancer Association: Japanese classification of gastric carcinoma: 3rd English edition. Gastric Cancer 14(2): 101-112, 2011. PMID: 21573743. DOI: 10.1007/s10120-0110041-5

20 Yang X, Song X, Zhang L and Wu C: Prognostic role of the pretreatment $\mathrm{C}$-reactive protein/albumin ratio in gastric cancer: A systematic review and meta-analysis. Medicine (Baltimore) 99(10): e19362, 2020. PMID: 32150079. DOI: 10.1097/MD. 0000000000019362

21 Yue L, Lu Y, Li Y and Wang Y: Prognostic value of C-reactive protein to albumin ratio in gastric cancer: a meta-analysis. Nutr Cancer: 1-8，2020. PMID: 32940549. DOI: 10.1080/016 35581.2020 .1817510

22 Toiyama Y, Shimura T, Yasuda H, Fujikawa H, Okita Y, Kobayashi M, Ohi M, Yoshiyama S, Hiro J, Araki T, Inoue Y, Mohri Y and Kusunoki M: Clinical burden of C-reactive protein/albumin ratio before curative surgery for patients with gastric cancer. Anticancer Res 36(12): 6491-6498, 2016. PMID: 27919972. DOI: 10.21873/anticanres.11248

23 Baba H, Kuwabara K, Ishiguro T, Hatano S, Matsuzawa T, Fukuchi M, Kumagai Y, Ishibashi K, Mochiki E and Ishida H: $\mathrm{C}$-reactive protein as a significant prognostic factor for stage IV gastric cancer patients. Anticancer Res 33(12): 5591-5595, 2013. PMID: 24324103.

24 Lee JW, Sharma AR, Lee SS, Chun WJ and Kim HS: The Creactive protein to albumin ratio predicts postoperative complication in patients who undergo gastrectomy for gastric cancer. Heliyon 6(6): e04220, 2020. PMID: 32577578. DOI: $10.1016 /$ j.heliyon.2020.e04220
25 Kanda M: Preoperative predictors of postoperative complications after gastric cancer resection. Surg Today 50(1): 3-11, 2020. PMID: 31535226. DOI: 10.1007/s00595-019-01877-8

26 Li SS, Udelsman BV, Parikh A, Klempner SJ, Clark JW, Roeland EJ, Wo JY, Hong TS and Mullen JT: Impact of postoperative complication and completion of multimodality therapy on survival in patients undergoing gastrectomy for advanced gastric cancer. J Am Coll Surg 230(6): 912-924, 2020. PMID: 32035978. DOI: 10.1016/j.jamcollsurg.2019.12.038

27 Sakuramoto S, Sasako M, Yamaguchi T, Kinoshita T, Fujii M, Nashimoto A, Furukawa H, Nakajima T, Ohashi Y, Imamura H, Higashino M, Yamamura Y, Kurita A, Arai K and ACTS-GC Group: Adjuvant chemotherapy for gastric cancer with S-1, an oral fluoropyrimidine. N Engl J Med 357(18): 1810-1820, 2007. PMID: 17978289. DOI: 10.1056/NEJMoa072252

28 Yoshida K, Kodera Y, Kochi M, Ichikawa W, Kakeji Y, Sano T, Nagao N, Takahashi M, Takagane A, Watanabe T, Kaji M, Okitsu H, Nomura T, Matsui T, Yoshikawa T, Matsuyama J, Yamada M, Ito S, Takeuchi $\mathrm{M}$ and Fujii $\mathrm{M}$ : Addition of docetaxel to oral fluoropyrimidine improves efficacy in patients with stage III gastric cancer: Interim analysis of JACCRO GC07, a randomized controlled trial. J Clin Oncol 37(15): 12961304, 2019. PMID: 30925125. DOI: 10.1200/JCO.18.01138

29 Tominaga T, Nonaka T, Sumida Y, Hidaka S, Sawai T and Nagayasu T: The C-reactive protein to albumin ratio as a predictor of severe side effects of adjuvant chemotherapy in stage III colorectal cancer patients. PLoS One 11(12): e0167967, 2016. PMID: 27930703. DOI: 10.1371/journal.pone.0167967

30 Saito H, Kono Y, Murakami Y, Shishido Y, Kuroda H, Matsunaga T, Fukumoto Y, Osaki T, Ashida K and Fujiwara Y: Prognostic significance of the preoperative ratio of C-reactive protein to albumin and neutrophil-lymphocyte ratio in gastric cancer patients. World J Surg 42(6): 1819-1825, 2018. PMID: 29270656. DOI: $10.1007 / \mathrm{s} 00268-017-4400-1$

Received August 26, 2021

Revised September 22, 2021 Accepted September 27, 2021 